\title{
9. Grounded Speed and the Soft Temporality of Network Infrastructure
}

\author{
Nicole Starosielski
}

\begin{abstract}
:
This chapter offers a descriptive view of cable temporality from the perspective of network operators and those involved in system maintenance and repair. Examining the "soft temporalities" of these operators' labor, the chapter illustrates a tension at the heart of media's infrastructures: in many places, slowness, stability, embeddedness, and fixity of infrastructures are what enable speed and acceleration. After describing the "grounded speed" of the cable network, the chapter turns to the phenomemon of temporal irruptions: moments when the assemblage of temporal processes that enable network operation and network speed suddenly and radically changes the network.
\end{abstract}

Keywords: undersea cable, infrastructure, slowness, telecommunications, network operation

Outside the thick concrete walls of a Pacific Island undersea cable station, the dense heat draws tourists to the beach and into the ocean. Many have come here to break from the accelerated rhythms of hyper-stimulated lives-a separation that some see as moving "out of time."1 For others, "island time" is a staged interruption in their acceleration, one that incorporates them into longstanding colonial temporal regimes. Inside the station, a different temporality is in operation. It is evident in the chilled air, where molecules have been slowed to an optimal temperature for machine operation. And it is evident in the building's sparse population, which exists in stark contrast to the crowded beaches. On the day that I visit the station, there are only a few employees on the clock. As one of them gives me a tour, he points to a laptop on top of a stack of servers. Here, he tells me, he could play

Volmar, A. and K. Stine (eds.), Media Infrastructures and the Politics of Digital Time: Essays on Hardwired Temporalities. Amsterdam: Amsterdam University Press, 2021 DOI 10.5117/9789463727426_CHо9 
video games with the least possible latency. His computer's position in the network's geography gives him a slight temporal advantage in real-time multiplayer online games. He is describing the spot-in a concrete building intensely insulated from the rest of the island, an island that is visited for its remoteness - where he is as close as possible to achieving network instantaneity. It is the place where his signals would travel faster than anyone else's, even in the many cities the nearby visitors have come to escape. Metaphorically and thermodynamically, this is both the hottest and the coldest point on the island. The temporality of the cable station inverts the rhythms of bodies beyond the walls: here, it is not that slowness provides a break from acceleration, but rather, that slowness makes possible extraordinary speed.

A century earlier, on another island in this same ocean, telegraph operators shared a similar sense of spatial and temporal disjuncture as they occupied the center and periphery at once. Sharing their stories in the cable industry magazine, they reflected on "the monotony of our slumberous existence," challenged one another to prove that they lived in the loneliest, most remote station, and looked forward even to the transient missionaries that might drop by in the summer and provide the smallest diversion from the banality of everyday life. ${ }^{2}$ The slowness of their world existed in stark contrast to the intensity, speed, and pace of the network they operated. This was often commented upon in stories and the company's internal communications. One operator remarked: "Though they have to wait three months for letters to be forwarded from Honolulu ... men on Midway can obtain news from nearly all parts of the world in a few minutes." ${ }^{3}$ For these telecommunications workers, as for the people they connected, the acceleration of communications could heighten the relative sense of the slowness of their nonelectric surroundings, including their own bodies and the labor that they performed.

These two examples, one from the early twentieth century and the other from a hundred years later, illustrate a critical point about the temporality of networked media: the speed of communication is often made possible by incredible investments in stasis, stability, and slowness-molecular, bodily, and architectural. While much interest in infrastructure's temporalities and microtemporalities has focused on acceleration, less research has examined the temporal dilations and prolongations that make acceleration possible. This, as Sarah Sharma points out in her foundational text In the Meantime, is a critical blind spot of speed theory. ${ }^{4}$ As she identifies in works from Paul Virilio's Speed and Politics to Jonathan Crary's 24/7: Late Capitalism and the Ends of Sleep, the focus on speed, time-space compression, and acceleration 
is often conducted from a position of temporal privilege, and often fails to account for the multiplicity of lived times that scaffold acceleration. ${ }^{5}$ This chapter brings Sharma's argument to bear on media infrastructures. It offers a descriptive view of cable temporality from the perspective of network operators and those involved in system maintenance and repair. Following Gabriele Schabacher in this volume, it sees hardwiredness "as a network effect with relative duration brought about by specific types of labor." If we consider the operations of these systems as solely a technical process, rather than a performance of situated and geopolitically-specific labor of care, we miss the complex, embodied temporalities of contemporary digital infrastructure. And as a result, we fail to account for the decisions involved in establishing, maintaining, and securing network infrastructure.

Like the taxi-cab drivers that transport global jetsetters in Sharma's study, there is a population whose everyday work and temporal coordination makes possible the speed of the network-in the case of the cable system, these include network operators, engineers, and suppliers, among many others. The everyday work of cabling involves, for today's operators, waking up in the middle of the night, interrupted from sleep by a broken cable. It includes the coordination of ship movements with weather patterns and the active routing of internet traffic. One thing that distinguishes network operators from many other laborers that maintain the acceleration of the global elite is a co-presence of extraordinary temporal privilege (and a concentrated personal investment in that speed) alongside a sense of an extraordinary slowness, prolonged activities of care, and relative stability. While this in itself is not unique-living in the midst of contradictory temporalities and oppositional rhythms is characteristic of modern life- the temporalities of these operators' labor illustrate a tension at the heart of media's infrastructures: in many places, slowness, stability, embeddedness, and fixity of infrastructures are what enable speed and acceleration. From the operator's standpoint, especially those that inhabit the cable station, these two extremes are often brought together in poetic opposition, innately intertwined, and perceptible in their bodies as an affect of remote centrality. I call this dynamic grounded speed: the ongoing production of accelerated rhythms through the consistency and regularity of network bodies, architectures, practices, and environments.

In the first half of this chapter, I describe the grounded speed of the undersea cable system. As a background for this analysis, I begin with a narrative about the larger-scale temporal patternings of the cable network. Some of the common descriptions of cable temporalities include: cables erase time; cables accelerate; and network infrastructures are significant 
because of their high speed and their microtemporal operations. In contrast to these typical observations, the second section reveals some of the varied decelerations, slowings, and stabilizings that make possible cable speed. First and foremost is the slowness of human navigation through the ocean. The slowness and sparseness of marine transport has produced relative safety for cable systems: more boats would produce more cable breaks. Next to this is the historical privileging of remote areas for centers of network traffic, where the frequency of human and machinic movement is less likely to disrupt or interfere with cable traffic. Lastly is the relative slowness of the cable industry, an insular community where extended relationships between operators emerge over years. This social world reproduces the cable network as an intimate and familiar landscape. Tracking cable industry labor, past and present, I show how the slowness of the network's milieu grounds the speed of interconnected global telecommunications.

Because network traffic is grounded-in the environments they extend through, in the rhythms of the bodies those who operate them, and in the patterned technics of their nonhuman milieus - the alteration of ground rhythms alters the speed of the system itself. If these typically balanced temporalities suddenly shift, the routinized temporality of an infrastructure is suddenly inflected by changes in its temporal milieu. I call these moments temporal irruptions: moments when the assemblage of temporal processes that enable network operation and network speed suddenly and radically changes the network. The fourth section of this essay charts how such irruptions along cable routes produce disruptions in the patterned time of the global network. Weaving through a set of breaks, disruptions, and irruptions in the cable network, I show how the elongated rhythms that keep networks safe can suddenly interrupt - and irrupt into—-the cable system. I argue that these irruptions direct our attention to the ongoing role of everyday, lived and embodied temporalities and the rhythms of cabled sociality, and the ways that infrastructures are "cyclical and repetitive processes of formation and transformation. ${ }^{n}$ As a complement to the hardwired temporalities that occupy much of this book, I call these soft temporalities, as they are the underbelly—a shifting and complex temporal substructure—of hardwired media and infrastructural times.

\section{Patterned Time}

In his well-known essay "Technology and Ideology: The Case of the Telegraph," James Carey demonstrates how the telegraph enabled the separation 
of physical objects from communication for the first time and, in doing so, was critical in the establishment of standard time, the transformation of futures markets, and the evolution of time contracts. ${ }^{7}$ Cable infrastructure, he showed, facilitated the production of modern, patterned time, and was an essential part of the temporal grid that restructured the industrial world. Undersea cables are the global links in this history, enabling the standardization of time on a global scale. An early function of undersea networks was to establish differences in longitude — which, as Richard Stachurski documents, "were literally a matter of time." ${ }^{8}$ One of the first uses of the transatlantic cable was to send star-transit timings that would help to determine longitude. The United States Coast Survey built temporary observatories at both ends of the cable, and between October and November 1866, clock signals were sent between the two locations on five different nights, "yielding the first directly-measured longitude of the dome of the U.S. Capitol west of the Greenwich Observatory: 5 hours 8 minutes and 2.22 seconds." ${ }^{9}$ The completion of the All-Red Line at the turn of the twentieth century - a British network that encircled the earth, was an infrastructure for the creation of Universal Standard Time. ${ }^{10}$ Today fiber connectivity via undersea cables enables the global coordination of digital time, and undergirds the precise operations of global positioning systems (GPS) among other digital operations.

Undersea cable systems, as was the case for telegraph systems generally, were perceived as annihilating time and space. This was true even within the cable industry. For example, in the cablemen's magazine, The Zodiac, many issues featured the final lines of Rudyard Kipling's "The Deep-Sea Cables": "They have wakened the timeless Things; they have killed their father Time." Although cable networks were understood to make time matter less, in actuality they substituted one form of temporal difference (in which temporal difference correlated with geographic distance) for another (a temporal difference that correlated with distance from infrastructure). In other words, the cable system produced a new set of temporal patternings in which elite users located in privileged positions felt synced with other elite users in privileged positions - they felt the distance between them less and less as temporal delay. In turn, cables introduced a new temporal structure in which those who did not have access to cabled systems or cabled information would more frequently perceived themselves as behind, delayed, and distant. In accelerating the production of a globalized temporality, whether through finance, news, or standardized time, the submarine telegraph also intensified a colonial temporal regime and was a means by which the Western empires were able to dominate the nineteenth-century timescape. 
Today's undersea cable networks, which carry $99 \%$ of transoceanic internet traffic, continue to restructure media temporalities in ways that parallel many of the telegraph's original impacts. In the world of highspeed trading, the cable system similarly both standardizes and accelerates machinic temporalities. This is especially true given the recent turn toward lower-latency cable systems. In network traffic engineering, latency is the amount of time it takes for a signal to make a round-trip between two terminals. Although the optimization of networks for speed has varied over the decades of cable laying, recent networks have been designed specifically as part of "low-latency" solutions. These have been developed to capture the market of high-frequency traders as well as for the range of computational practices that are dependent on speed-from cloud computing to the navigation of remote vehicles.

Take for example the 2015 Hibernia Express cable, which introduced a new low-latency path between New York and London-clocking in at 58.95 milliseconds. ${ }^{11}$ In 2017, the Seabras-1 submarine cable supplied Seaborn Networks with a "proprietary ultra-low latency (ULL) solution" (SeaSpeedTM) between the BM\&F Bovespa Stock Exchange in São Paulo, Brazil and Carteret, New Jersey. ${ }^{12}$ Geography and the shortest route isn't the only factor in latency - other technical factors include the refractive index of the fiber, the number of amplifiers, and the process of equalizing the fibers. ${ }^{13}$ Other traffic-related factors include network congestion, firewalls, and over-used routers. As one operator describes: "This also means that the integration for the land and sea routes must be taken into account, every interface can add latency."14 Achieving speed in the cable network never occurs merely through reduction of geographic distance, it often involves a consolidation of technical interfaces and a reconfiguration of social practice. Just as cable systems do not simply erase time, but re-pattern it differently for different publics, the production of the cable's temporal dynamics does not simply involve acceleration, but are a complex temporal and social operation.

\section{Grounded Speed}

What is often missing from these descriptions of cable speed are embodied practices that prop up acceleration-labor and social worlds assembled into fixed rhythms. Pulling its workers into a set of patterned times, the early telegraph system often sped up their movements and synced them to a machinic temporality. Some operators were required not only to meet a minimum speed, but also to ensure accuracy at this speed. As the poem, 
"Cablemen," describes cable work: "we work 'em like clockwork ... We must work them like lightning,/ Must work 'em pell mell,/ For it's through the thin cables/The Empire can tell/That all her Dominions and Children are well." ${ }^{\prime 5}$ H.F.B., the poem's author, describes the work of the cablemen as both "like clockwork" and "like lightening," drawing connections to the machinic and natural world to articulate the routinization and inhuman speed of the operator's body, all in service of the British Empire. The patterning of the men's bodies was structured by and in turn scaffolded British colonial expansion. Another cableman laments the lack of recognition for the men in the middle: "do you ever think how men/ Have worked the whole night through,/ And done the best within their ken/ to rush that Press-work through?"16 These descriptions of the operators' work echo throughout the cable magazines, with their details about late-nights and extended hours, immediacy to global events, the repetitive sounds of clock and telegraph, and the "dull routine" that propels the world forward. ${ }^{17}$ As Sarah Sharma writes: "Temporalities are not times; like continually broken clocks, they must be reset again and again. They are expected to recalibrate and fit into a larger temporal order." ${ }^{\prime 18}$ The temporality of the cable network was anchored in the ongoing recalibration of cable workers' embodied temporalities.

This patterning was not only machinic — keyed by the telegraph and modulated by cable. It was and continues to be social. In the telegraph era, regulations governing the rhythms of everyday life were intended to stabilize men's bodies, and as a result, the network's operation. One cable operator recounted his time at the Southport Station in Australia, where for probationers, "Church attendance once on Sundays was compulsory, and there was a 10 p.m. curfew ... The use of lamps in bedrooms was forbidden."19 Here the use of modern technologies of light were forbidden (even as candles were allowed) as part of the regulation of the men's nighttime activities. This ensured their adherence to a temporal pattern that would keep the cable system operational. In the telephone cable era, more complex technological systems would be deployed as a means of managing time and timing. For example, aboard the cableship Neptun, an internal CCTV network enabled "split-second timing" in cable laying operations_and for cable-laying operators. $^{20}$

The operators of the Eastern Telegraph System thus held together a number of overlapping temporalities in their own bodies. On one hand, they perceived their own role as an extension of the cable, annihilating temporal distance between Britain and the colonies. They both upheld its speed, with the actual speed of transmission reflecting the cumulative capabilities of 
all operators on the route, and saw themselves as the very first receivers: in 1926, one author remarked: "The work of a cable operator is a business of thrills and chills, though many imagine it to be a humdrum, mechanical occupation. You never know what is coming next. Cable operators have early news of world-shaking events." ${ }^{21}$ They occupied the subjective position, as with many other inhabitants along the colonial lines, in which a colonial temporal regime (the location of Britain as ahead) materialized in the technological extension of the cable system. At the same time, stationed at remote outposts around the world, as the anecdotes at the opening of this chapter testify, the cablemen were keenly aware of the continued temporal and geographic distance that positioned them at the fringes of empire. As they waited for supply ships, for letters and visitors to arrive, and for seasons to shift such that the environment would become passable, the cablemen's daily worlds shifted very slowly. The curfews, regulation of activity, and patterning of social exchanges in the cable station provided a slow and tedious rhythm of everyday life. Beyond this, a sense of slowness was produced in their extended posts at colonial hubs: the cable staff at any given location might remain in a given outpost for years. This strategic choice of the system managers would in turn help to establish continuity at the stations themselves.

Slowness, drag, and longer rhythms of movement did not inhibit the system - they constituted it. For the cablemen this sense of delay and stasis, perceived in their bodies and communicated through their internal magazines, intensified the sense that the environment surrounding them was "backward" or slow. At the same time they experienced an extraordinary temporal privilege. This sociotechnical and affective dynamic is what I describe as grounded speed. Today, grounded speed is the temporal substrate of undersea digital infrastructure, and can be best perceived in the processes of network construction, operation, and maintenance. The establishment of new cable networks continues to take years in planning, financing, and construction. Part of this process involves sending a survey ship to carefully document the prospective ocean route. In installation, the cable is coiled into a tank on the back of a cable ship, and dropped off the stern as the vessel crosses the ocean. The cable rests on the seafloor for the duration of its life, sometimes for decades without being disturbed. If the cable is broken, even if the ship is deployed to the fault location immediately, it might still take days or even weeks for the cable to be repaired, especially if the cable's owners are waiting to acquire permits for repair. All of these activities take time, and the duration of this process is extended by the slowness of marine transport, the need for careful operations, the tangled permitting 
process that occurs in some territorial waters, and the fact that once on the seafloor the cable cannot easily be retrieved. In other words, the difficulty of negotiating with the aquatic and political environment ground the system, making it relatively fixed once established, and discourage replacement. In turn, the ocean itself and the lack of human contact protects the cable, ensuring its continued speed.

Grounded speed is also present in the bodies of cable operators, though they are no longer confined to cable stations in remote outposts. Instead, many sit at screens in network operations centers (NOC), waiting for "alarms" to tell them what parts of the network need to be checked or repaired. The latest network operations technologies might release them from these screens, enabling the delivery of alarms via text message or smart phone. Whether in a NOC or not, the cable operators' bodies stay at attention and their movements are calibrated such that they can attend to the network at a moment's notice. Checking the network involves routine trips to a set of locations, including cable stations and beach landings. It involves regular maintenance and cleaning of these locations. While waiting for alarms keeps cable operators holding focus, ready to react at all times, ongoing maintenance is intended as a preventative measure, one that will forestall disruption through routine practices. In both of these cases, grounded speed exists in operation: signals keep flowing through the system at accelerated rates because of cable operators' repetitive motions, their familiarity with a narrow set of routes, and their relative stasis.

Another way that grounded speed exists in cable operation is in the relative stasis of the cable industry. Many people who work to construct undersea cable systems, whether in supply, marine operations, management, and even sales, have been in the industry for decades. In a recent presentation at the SubOptic conference, the triennial event of the subsea cable industry, analyst Kristian Nielsen described the problem of the "generation gap," and to prove his point, asked the members of the audience to keep their hands raised if they had been in the cable industry for more than twenty years. His audience, with many of their hands in the air, already understood his point: they had worked with the same set of people since at least the 1990s. While Nielsen and others have identified this as a problem in the industry - there are not very many younger members to take the place of the existing cable labor force-the lack of turnover and the ongoing stable presence of industry veterans grounds the system. Their continued practice ensures continuity of operation, availability of knowledge, and a vast archive of past negotiations with difficult social and environmental actors. The system stays intact precisely because of the lack of change in 
the cable world's social fabric. Repetition (whether social or machinic), prolongs interactions and slowness scaffolds speed.

\section{Temporal Irruption}

At the bottom of the Luzon Strait, relatively little changes. Sediment shifts and marine creatures move, but the cables that extend through in this narrow stretch between the Philippines and Taiwan stay in place. Cables might shift slightly on the seafloor, but they rarely travel great distances. The ocean is a stable and continuous context for cable systems.

In 2006, the ground suddenly shifted. The Hengchun earthquake triggered a subsea landslide. It was not the sudden movement of the earth's tectonic plates that severed the cables, but the subsea landslide that sent waves of sediment hurling down the seafloor. When accumulating slowly over time, sediment itself does not disrupt a cable — many systems are buried at their shore ends. But the shift in ecological temporality, the deviation from the existing pattern of subsea currents and sediment motion, irrupted into the temporal patterning of the cable system. Suddenly network traffic stopped across the cable. Users at various locations suddenly could not load webpages or send email. They were stalled, temporarily stopped by an irruption of re-patterned deep-sea time.

Temporal irruptions are not simply the moments when a system fails. They are indications that the ground that sustains infrastructure operation has fallen out of sync. They are moments when the shifting temporality of other phenomena - of ocean and atmosphere; of operators and inhabitants - alter the rhythms of the cable network and the internet as a whole. While undersea cables are largely secured from human interference in the ocean's depths, terrestrial fiber optic cables are regularly disrupted by ongoing projects of ground disturbance, especially digging along the cable route. Local construction projects, which involve the shifting and redevelopment of architecture, power lines, and water lines among others, often involve digging. This shift in an otherwise stable temporal patterning likewise irrupts into the network, causing a temporal disruption. In the ocean, storms have caused ships to put down anchor, stabilizing themselves in an otherwise tumultuous sea, but in turn severing cable systems. These are not mere moments of environmental interference, they are moments of temporal disjuncture.

In moments of irruption, network time is out of sync. The slowness, the cycles, and the patterns that had previously grounded the cable network then prevent the network from resuming at speed. Take for example this 
problem in the case of Arctic undersea cables. While cables always take time to repair, in the Arctic frozen ice can inhibit a cable ship's passage for a significant part of the year. If a cable breaks during this period, one operator reflects, "you need to sustain a fault for months sometimes." ${ }^{22}$ The rhythm of environmental phenomena, jarred out of sync with the network itself, no longer serves as a continuous shelter, a ground for the system. Instead, operators must find other ways-whether other cables or environments - to sustain network traffic and temporal operations.

\section{Conclusion}

Over the past decades, media studies scholars have documented the temporal regimes of network technologies, from the manipulations of infrastructural optimization and efficiency, to the emergent microtemporalities of digital systems, to planned social and technological obsolescences. This chapter shows that the system of submarine cables is an infrastructure that helps to prop up these temporal regimes, facilitating distinct and historically-specific patternings of time. It facilitates synced, standardized and universal time, but it has also propped up varied colonial, capitalist, and globalized temporal regimes. Looking beyond the hardware of cable systems, this chapter's study of network operations reveals the ways that all of these regimes depend on the syncing up of numerous human and nonhuman temporalities. Machinic time produced via cable systems is inevitably interlaced with social and environmental time - the reconfiguration of machinic time is both dependent on the organization of the temporality of labor and seasons, and exists within its limits. Undersea cables are relatively stable infrastructures compared to most digital systems, and this is in part due to a multitude of extended and embodied rhythms: from the operators standing by to the social fabric of cable landing stations and management centers, where the goal is always stasis.

In these sites, the human-machine interface is always also a temporal interface, where the patterned time of cable systems is enfolded in a multiplicity of other time-scales and temporal practices. If technical systems hardwire media and social practice in a variety of ways, these systems are nonetheless inevitably tethered to soft temporalities. Soft temporalities are those that are variable, exist beyond the machinic, and emerge in embodied practice. If hardwired temporalities encode temporal regimes and govern activity, the soft temporalities of digital infrastructure comprise both its base layer and its most vulnerable context. 


\section{Notes}

1. Phillip Vannini, "In Time, Out of Time: Rhythmanalyzing Ferry Mobilities," Time \& Society 21, no. 2 (2012): 241-269.

2. "The Gooney Clarion," The Zodiac: The Journal of the Submarine Cable Service, 6 (June 1912-May 1913): 61-72; "The Lonliest Station," The Zodiac: The Journal of the Submarine Cable Service 10 (June 1917-June 1918): 109.

3. "The Trail of Lonesome Midway," The Zodiac: The Journal of the Submarine Cable Service 9 (June 1916-June 1917): 116.

4. Sarah Sharma, In the Meantime: Temporality and Cultural Politics (Durham, NC: Duke University Press, 2014).

5. Paul Virilio, Speed and Politics (Los Angeles: Semiotext(e), 2007); Jonathan Crary, 24/7: Late Capitalism and the Ends of Sleep (London: Verso, 2013).

6. Gabriele Schabacher, "Time and Technology: The Temporalities of Care" (this volume).

7. James W. Carey, "Technology and Ideology: The Case of the Telegraph," Prospects 8 (1983): 303-325.

8. Richard Stachurski, Longitude by Wire: Finding North America (Columbia: University of South Carolina Press, 2009), 15 .

9. Trudy Bell, "The 'American Method': The 19th-Century Telegraphic Revolution in Finding Longitude" (work-in-progress paper presented at the IEEE Conference on the History of Telecommunications, St. John's, NL, Canada, Friday, July 27, 2001), 6.

10. Notably, Sandford Fleming, the Canadian who had proposed the adoption of Universal Standard Time, was also the principal proponent for the AllRed Line.

11. TeleGeography, "Trans-Atlantic Network Latency Reduced," The Broadcast Bridge, October 9, 2015, https://www.thebroadcastbridge.com/content/entry/3988/trans-atlantic-network-latency-reduced.

12. Seaborn, "Spread Networks and Seaborn Team Up to Provide SeaSpeed ${ }^{\mathrm{TM}}$ : Brazil's First Dedicated Ultra-Low Latency Subsea Route," SeabornNetworks. com, May 8, 2017, https://seabornnetworks.com/spread-networks-and-seaborn-team-up-to-provide-seaspeed-brazils-first-dedicated-ultra-low-latency-subsea-route/.

13. Alasdair Wilkie, "Low Latency Cables" (paper presented at SubOptic Conference, Paris, 2013), https://www.suboptic.org/wp-content/uploads/2014/10/NO02_Poster_105.pdf.

14. Wilkie, "Low Latency Cables."

15. H. F. B, "Cablemen," The Zodiac 9 (June 1916-June 1917): 211.

16. Crispian, "Cable (K)nights," The Zodiac: The Cableman's Paper 8, no. 85-96 The Zodiac: The Journal of the Submarine Cable Service, vol. 9 (June 1916June 1917): 44 .

17. R. M. M., "The Man at the Key," The Zodiac (March 1917): 227.

18. Sharma, In the Meantime, 7 . 
19. "Early Days at Southport," State Archives, Southport Australia, Premiers Papers Re: Pacific Cable, 6.

20. “Candid Camera ... NEPTUN Version!" Underseas Cable World: A Bi-monthly report by U.S. Underseas Cable Corporation 1, no. 3 (Feb-March 1967).

21. George E. Clarke, "Cable Thrills," The Zodiac: The Submarine Cable Service Paper 17, no. 210 (1926): 316.

22. Hector Hernandez, "The Push for Polar Projects: Challenges and Remedies Impacting the Design and Implementation of Arctic Submarine Cable Systems" (paper presented at SubOptic Conference, New Orleans, April 11, 2019).

\section{About the Author}

Nicole Starosielski, Associate Professor of Media, Culture, and Communication at New York University, is author of The Undersea Network and Media Hot and Cold, and co-editor of Signal Traffic: Critical Studies of Media Infrastructure, Sustainable Media: Critical Approaches to Media and Environment, Assembly Codes: The Logistics of Media and the "Elements" series (Duke University Press). 
